\title{
AC 2010-996: CONVEYING THE IMPORTANCE OF MANUFACTURING PROCESS DESIGN USING SIMULATION RESULTS AND EMPIRICAL DATA
}

\section{Michael Johnson, Texas A\&M University}

Johnson is an assistant professor in the Department of Engineering Technology and Industrial Distribution at Texas A\&M University. Prior to joining the faculty at Texas A\&M, he was a senior product development engineer at the 3M Corporate Research Laboratory in St. Paul, Minnesota for three years. He received his B.S. in mechanical engineering from Michigan State University and his S.M. and Ph.D. from the Massachusetts Institute of Technology. Johnson's research focuses on design tools, specifically, the cost modeling and analysis of product development and manufacturing systems; CAD methodology; and engineering education.

\section{Ram Prasad Diwakaran, Texas A\&M University}

Diwakaran received his Bachelor of Engineering (Hons.) in Mechanical Engineering from Birla Institute of Technology and Science, Pilani, India in 2005. He is currently pursuing a MS in Mechanical Engineering from Texas A\&M University.

\section{Justin Zsiros, Texas A\&M University}

Justin Zsiros is currently finishing his MS in Manufacturing Engineering Technology at Brigham Young University after completing an MBA from Texas A\&M University (2009), and a BS in Manufacturing Engineering Technology from Brigham Young University (2007). His thesis research is in the area of natural fiber thermoplastic composites. He has taught plastics and composites labs for four years at Texas A\&M and Brigham Young University. 


\title{
Conveying the Importance of Manufacturing Process Design Using Simulation Results and Empirical Data
}

\begin{abstract}
Manufacturing combines many aspects of engineering and technology. To achieve the desired results, manufacturing engineers must understand how component design, processing equipment design, and process parameters affect the final component. Currently, engineers have access to manufacturing simulation tools in addition to empirical tests. This allows engineers to test theories and do preliminary analyses of manufacturing processes (with simulation tools).

To understand how a process will perform and ensure the desired results usually requires empirical data. Injection molding is a widely used and easily understood process. There are simulation tools available for the injection molding that are accessible to undergraduate engineering and technology students. When simulations performed using these tools are combined with empirical results, students can better comprehend the usefulness and limitations of such tools.

This paper details a laboratory exercise which demonstrates to students how gate location affects the stress and strain properties of injection molded tensile test specimens. The effects of process parameters are also shown. Students are shown process simulations of injection molding using varying parameters and gate locations. They then injection mold tensile test specimens and test them. These results demonstrate the importance of process parameters (e.g., injection pressure, temperature, etc.) and gate location. Process parameters are shown to have a significant effect on the ability to produce an acceptable specimen. Gate location is also shown to affect stress-strain behavior.
\end{abstract}

\section{Introduction}

Manufacturing is a multidisciplinary that leads to the realization of engineering designs. Students studying manufacturing engineering and manufacturing engineering technology will be expected to use unprecedented amounts of technology to assist in this realization as they enter the workforce. While manufacturing is just one part of a product development process that is becoming more and more important, it is a critical part that can lead to and affect significant investments. Conveying to students the role of technology (and its limitations) should be incorporated into manufacturing engineering and manufacturing engineering technology curricula.

There have been significant advances in computer simulation in recent years. Some have predicted that computer-aided engineering will eliminate the need for prototypes [1]. There are numerous simulation tools of varying rigor and complexity available for manufacturing simulation (e.g., Moldflow or PAM-STAMP). The complexity of building a reliable computer prediction has been noted; when empirical data is absent there is ignorance [2]. A necessary step of producing a reliable model is the comparison of the observed physical event with the prediction of the mathematical model; this is referred to as validation [2-3]. 
In addition to validation, the ability to relate process parameters and simulation results to some desired performance goal is also needed. To introduce students to manufacturing simulation software and illustrate its ability to help produce components that meet desired performance goals, a simulate, manufacture, test exercise is detailed. The details of this exercise and the results are detailed in the following sections.

\section{Exercise Description}

To convey the role that manufacturing simulation can have in manufacturing and show students how simulation results can affect desired qualities, an exercise for a polymer manufacturing course was developed. This course is taken by sophomore and junior level students in a combined manufacturing and mechanical engineering technology course. The course focuses on various polymer manufacturing processes (e.g., casting, molding, extrusion, etc.). This exercise altered the existing injection molding laboratory in the class. The laboratory sections usually consist of 12-16 students.

The exercise incorporated simulating the manufacture of, manufacturing, and testing tensile test specimens. The tensile specimens were $6.35 \mathrm{~cm}$ in total length. Each lab section was split into three groups; one for each of the gate locations examined and where they would perform or be assisted in doing the three tasks associated with the laboratory (simulation, manufacturing, and testing). The three gate locations included the middle of the specimen, the end of the specimen, and the side of the specimen (see Figure 1). The injection molding simulation was carried out with the Autodesk Inventor Mold Design Tool. The students were given some brief background about injection molding simulation and shown how the program takes the component geometry and then creates a mold. They were also shown how the material information (Marlex 9012 high-density polyethylene) is incorporated into the simulation. Next they were told about the processing capabilities (temperature and injection pressure) of the laboratory injection molder and asked to provide estimates for these parameters. They were then shown the suggested processing parameters provided in the material data file (these were within the range of the machine used) and asked if they wanted to use these parameters. Next they were shown a simulation of the filling of the mold using the parameters chosen. Contour plots of quality prediction, air traps, and weld lines were also shown. The students were then told to proceed to the next station: manufacturing.

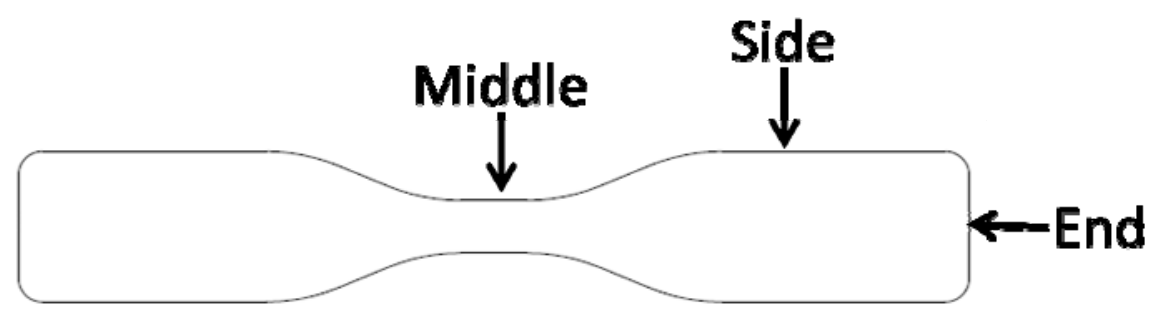

Figure 1. Sample diagram with alternative gate locations shown.

The manufacturing of the tensile test specimens was carried on a table top injection molding machine from AB Machinery - the AB 400 (see Figure 2a). The machine allows for the setting of injection temperature, injection pressure, clamp pressure, injection time (packing time), and clamp time. The students were given an insert that corresponded to the gate location for their 
group and asked to mold four usable specimens. They were told to record the processing parameters used to produce the four usable specimens. The instructor or a teaching assistant was available to assess the usability of the produced specimens. Once the usable specimens were produced, the students proceed to the testing station.

The samples were tested on a Tinius Olsen H10KT tensile testing machine. They were extended at $0.02 \mathrm{~cm} / \mathrm{s}$ and the test continued until the failure (fracture) of the specimen. The students noted the elongation to break (strain) and ultimate strength (Mpa) of the specimens. Given that the three groups had to begin at various stations to make the laboratory time effective, samples were given to the initial testing group to test. The group that began with testing moved to the simulation station next.

Once the three groups had completed the three different exercises at the three stations, they met and discussed their results and finding. The goal was to have them try to determine what the best gate location was given the results that all three groups produced.

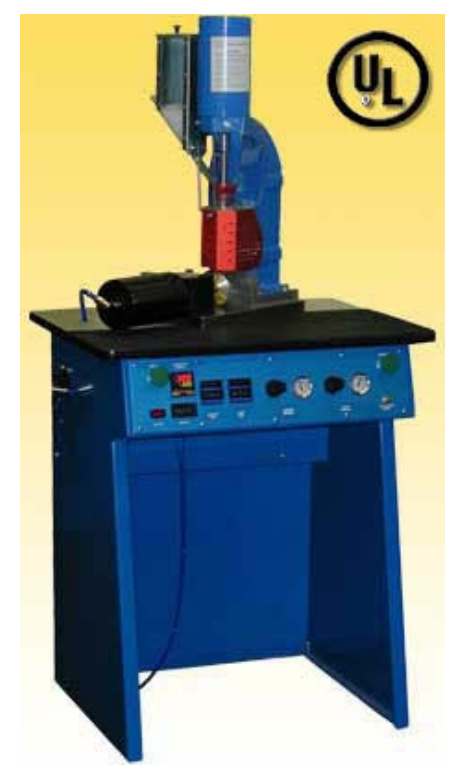

a.

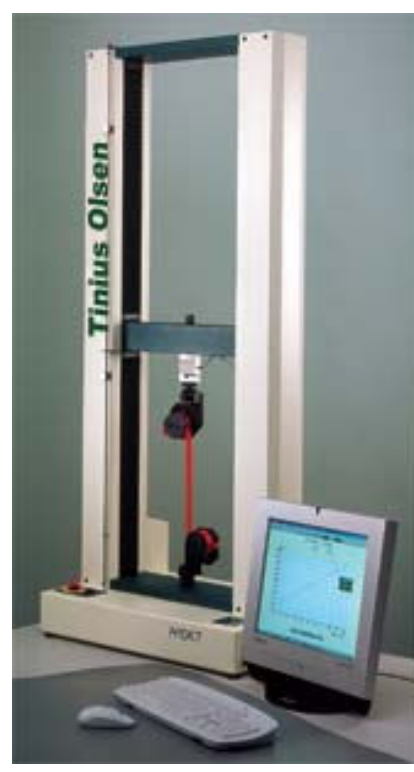

b.

Figure 2. Manufacturing and testing equipment: a) AB-400 Table Top Injection Molder; b) Tinius Olsen H10KT.

\section{Results}

The results of the fill simulations are shown in Figure 3. All samples were able to fill. The specimens with the gates at the end had a higher strain and a higher ultimate strength. Those with the gate in the middle performed poorly in both strain to break and ultimate strength. This was due to the defect produced by the gate in the middle of the gauge length. 
Table 1. Tensile Testing Results

\begin{tabular}{|c|c|c|}
\hline Gate Location & $\begin{array}{c}\text { Strain to Break } \\
(\mathrm{cm} / \mathrm{cm})\end{array}$ & $\begin{array}{c}\text { Ultimate } \\
\text { Strength }(\mathrm{MPa})\end{array}$ \\
\hline Side & 18.47 & 28.48 \\
\hline Middle & 2.66 & 22.70 \\
\hline End & 26.14 & 34.23 \\
\hline
\end{tabular}

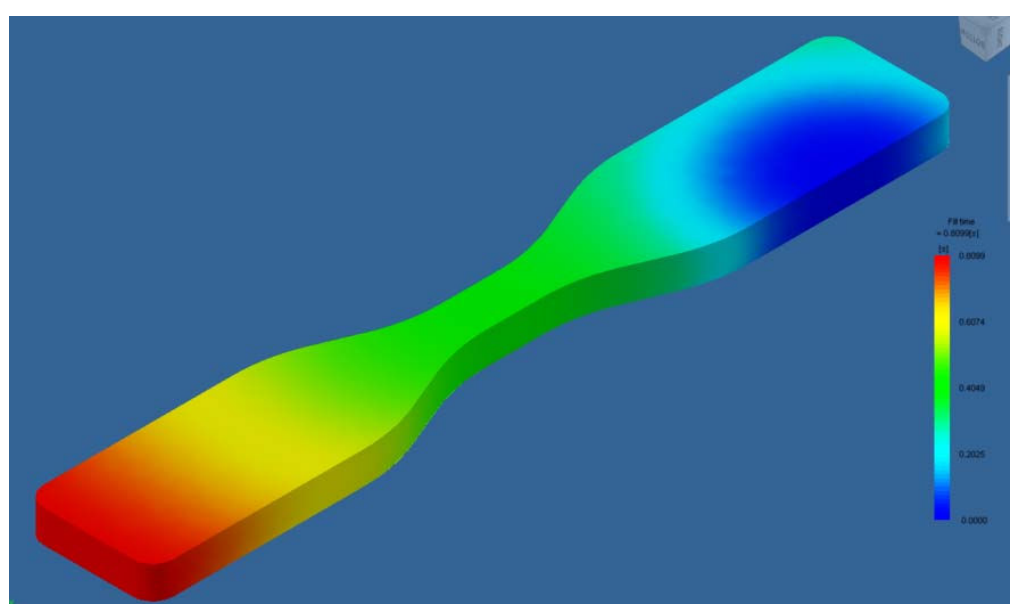

a.

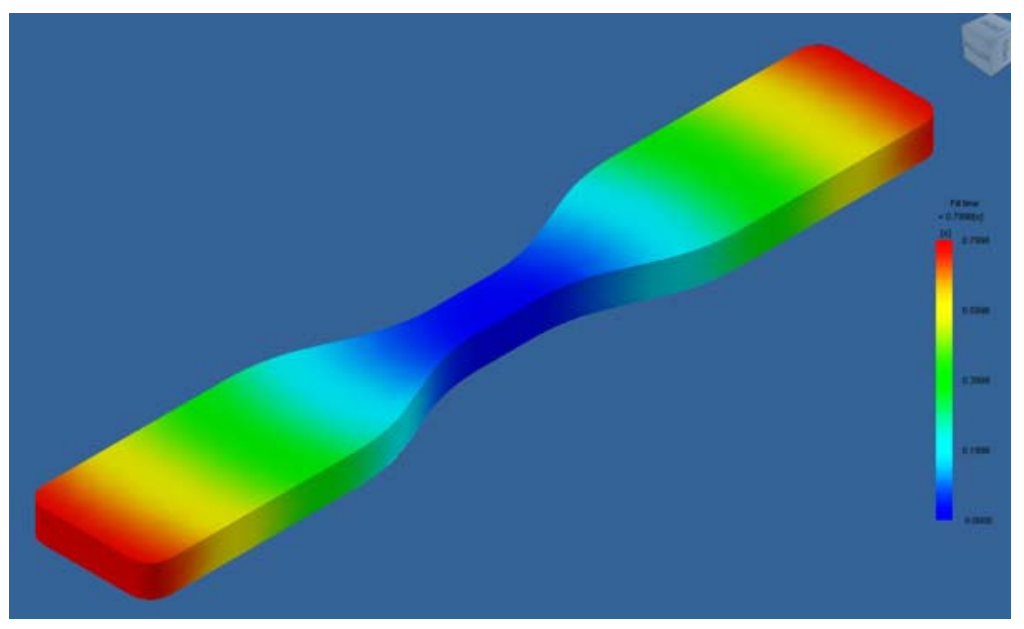

b. 


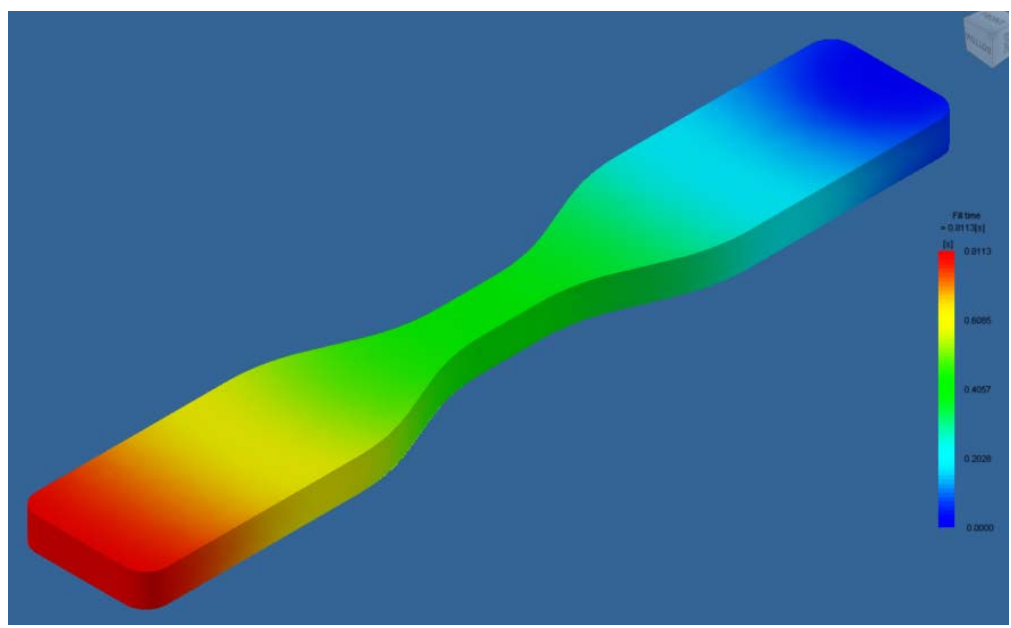

c.

Figure 3. Fill time contours: a) side; b) middle; c) end.

\section{Conclusions}

This exercise entailed conveying the ability of a manufacturing process to produce components that met some desired goal. This was done using injection molding simulation and the role of gate location on the performance of tensile test specimens. The specimens with the gate located at the end performed better than the two alternatives. The specimen with the gate at the side performed comparably to the end gated specimen, but the specimen with the gate in the middle performed poorly.

Students were introduced to manufacturing process simulation software. Students were able to experience the effects of processing parameters on the ability to produce viable components via simulation software. Students were able to see how gate location affected performance and role of processing parameters through simulation. Students remarked that the overall experience was informative and showed interest in gaining more "hands-on" experience with the software. This remains a goal for future activities.

\section{Bibliography}

1. J. K. Liker, et al., "Fulfilling the Promises of CAD," Sloan Management Review, vol. 33, pp. 74-86, Spring 1992.

2. I. Babuska and J. T. Oden, "The Reliability of Computer Predictions: Can They be Trusted?," International Journal of Numerical Analysis and Modeling, vol. 3, pp. 255-272, 2006.

3. I. Babuska and J. T. Oden, "Verification and Validation in Computational Engineering and Science: Basic Concepts," Computer Methods in Applied Mechanics and Engineering, vol. 193, pp. 4057-4066, 2004. 